\title{
A Human-Autonomy Teaming Approach for a Flight-Following Task
}

Summer L. Brandt

Rickey Russell

San Jose State University/

NASA Ames Research Center

SJSU SAN UOSE STATE
Joel Lachter

Jay Shively

NASA Ames Research Center

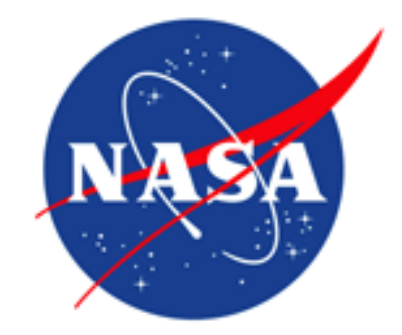




\section{Problems with Automation}

- Incidents and accidents result from pilots failing to understand increasingly sophisticated aircraft systems

- These systems are often brittle and rarely degrade gracefully

- Automation helps when all goes well but leaves the human out-of-the-loop when it fails

- Automation interfaces often lack transparency, not facilitating understanding or tracking of the system

- Disuse and misuse of automation (miscalibrated trust) have lead to real-world mishaps and tragedies

- Human involvement with increasingly sophisticated automated systems must adjust to allow for a more dynamic relationship involving cooperation and teamwork 


\section{Purpose}

- Part-task study to demonstrate, evaluate and refine proposed tenets of humanautonomy teaming (HAT)

- Bi-directional communication

- Transparency

- Operator-directed interface

- Built on an earlier ground station to minimize development and focused primarily on interactions with one piece of software

- Overall goal is to develop a framework for HAT in aviation and provide guidelines and recommendations for its application 


\section{HAT Simulation: Tasks}

- Participants: 4 Dispatchers, 2 Pilots

- Participants, with the help of automation, monitored aircraft

- Alerted pilots when

- Aircraft was off path or pilot failed to comply with clearances

- Significant weather events affect aircraft trajectory

- Pilot failed to act on EICAS alerts

- Rerouted aircraft when

- Weather impacted the route

- System failures or medical events force diversions

- Ran two 50-min scenarios, containing approximately 40 aircraft and 6 offnominal events

- One scenario with HAT tools, one scenario without HAT tools 


\section{Autonomous Constrainted Flight Planner}

ELP: Emergency Landing Planner (2007-2012)

- Cockpit decision aid

- Route planning for (serious) emergencies

- control system failures

- physical damage

- fires

- Time \& safety were dominant considerations

ACFP: Autonomous Constrained Flight Planer (2013-2017)

- Ground station decision aid

- Diversion selection, route planning, route evaluation

- weather diversion

- medical emergencies

- less critical system failures 


\section{Emergency Page on the CDU}

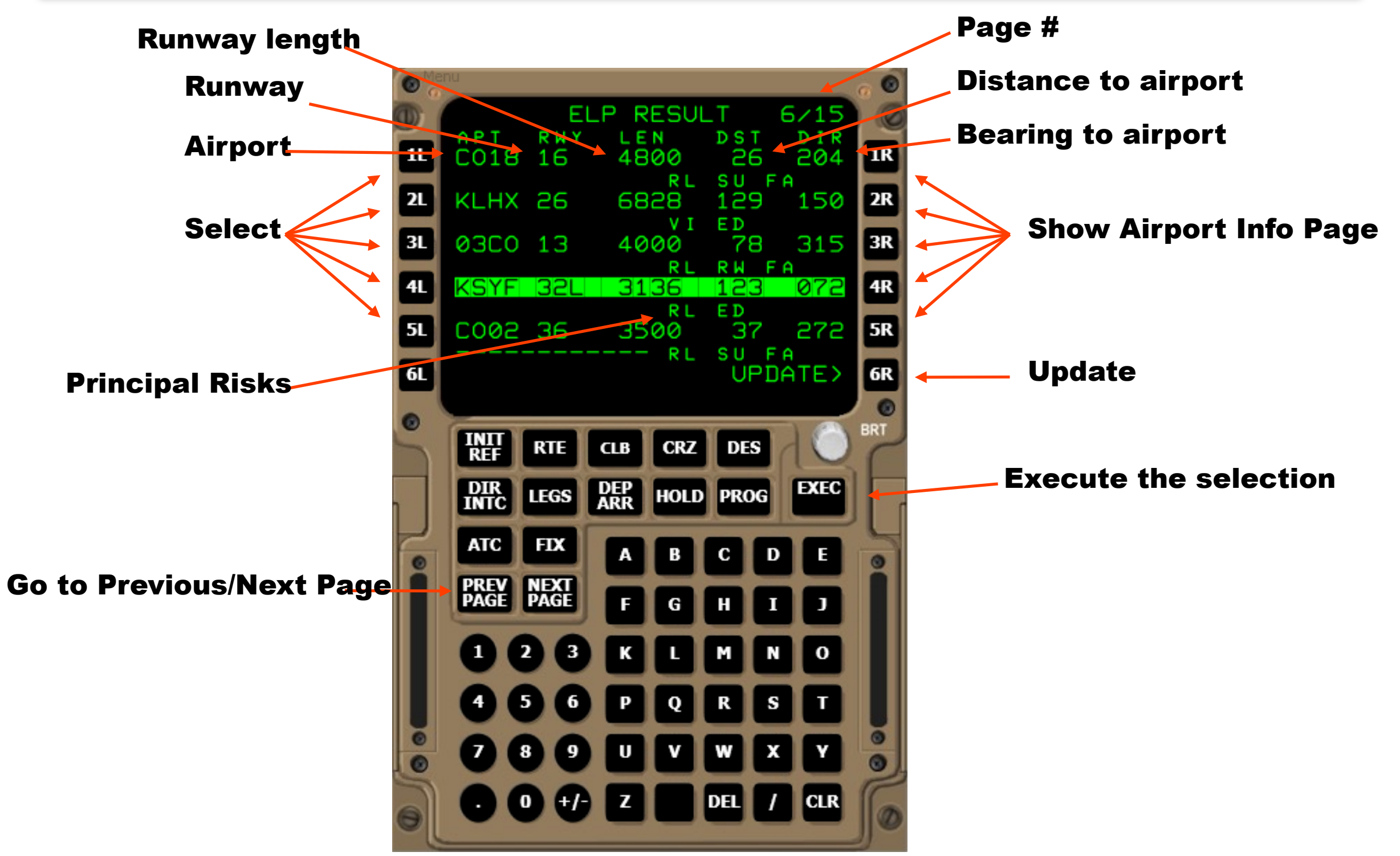




\section{Simulated Ground Station}

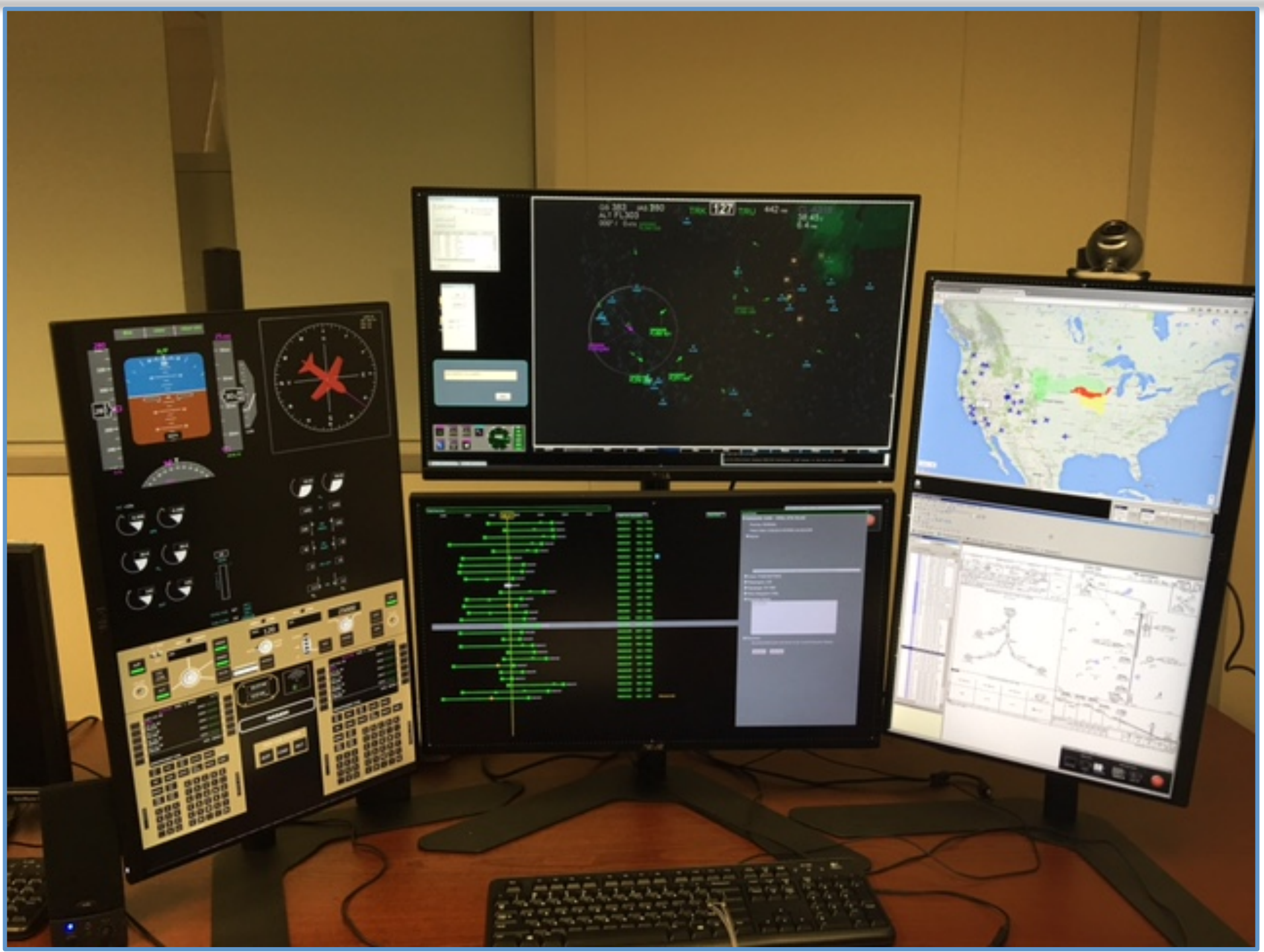




\section{Building in HAT Tenets to the Ground Station SJSU SAN JOÉ STAT}

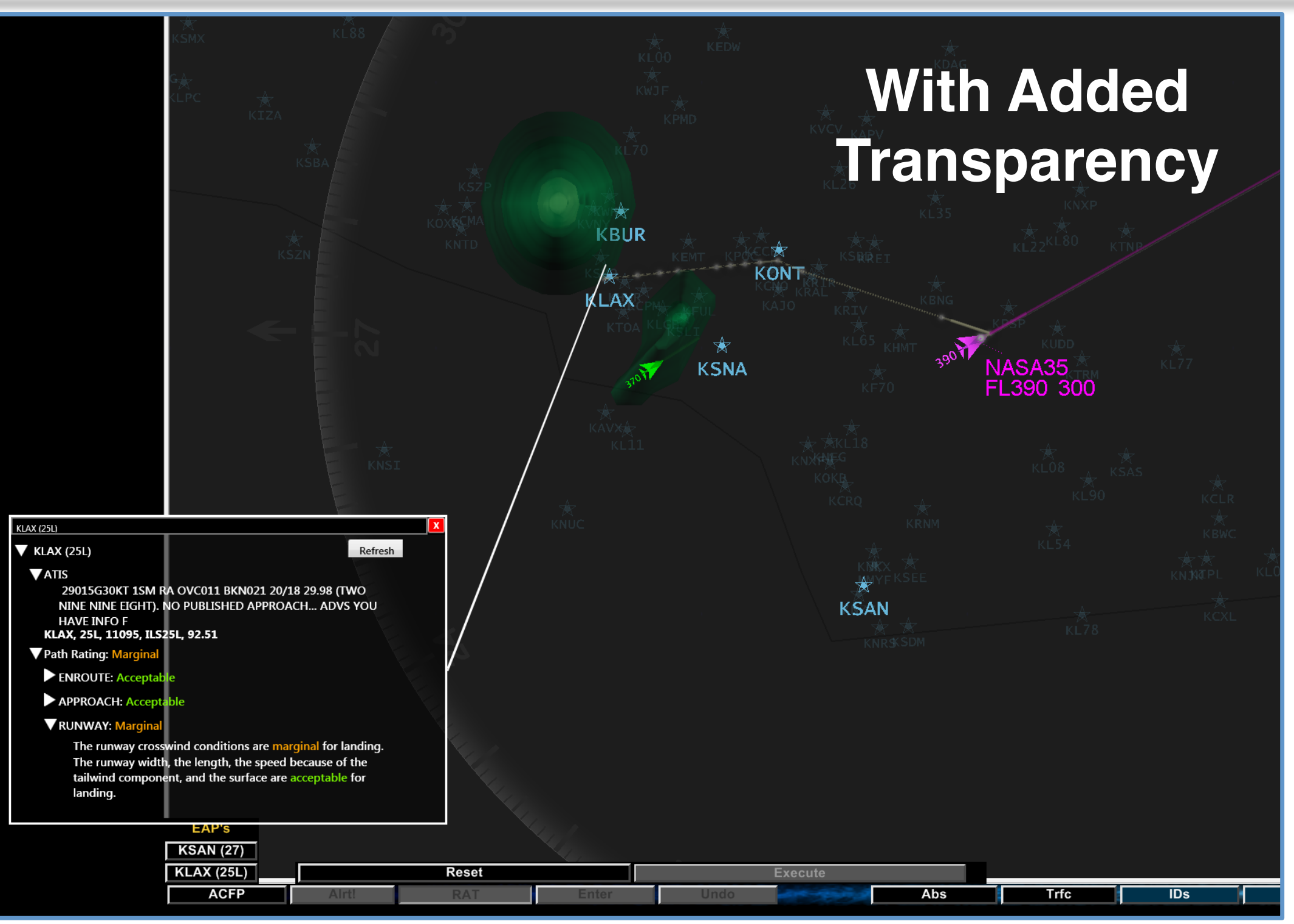




\section{Building in HAT Tenets to the Ground Station SJSU SAN OSÉ STATE}

- Human-Directed

- Operator calls "Plays" to determine who does what

\begin{tabular}{|c|c|c|c|c|}
\hline Anti-skid Fail & Anti-ice fail & $\begin{array}{c}\text { Windshield } \\
\text { Overheat }\end{array}$ & $\begin{array}{c}\text { Wheel Well } \\
\text { Fire }\end{array}$ & Wx Radar Fail \\
\hline No Auto-Land & $\begin{array}{c}\text { Cabin Pressure } \\
\text { Fail }\end{array}$ & $\begin{array}{c}\text { Medical } \\
\text { Emergency }\end{array}$ & $\begin{array}{c}\text { Auto-Brake } \\
\text { Fail }\end{array}$ & Cabin Fire \\
\hline \begin{tabular}{c|c|c|}
\hline $\begin{array}{c}\text { Cargo Door } \\
\text { Open }\end{array}$ & Divert & Weather \\
\hline
\end{tabular} \\
\hline
\end{tabular}

- A play encapsulates a plan for achieving a goal. It includes roles and responsibilities

- what is the automation going to do

- what is the operator going to do

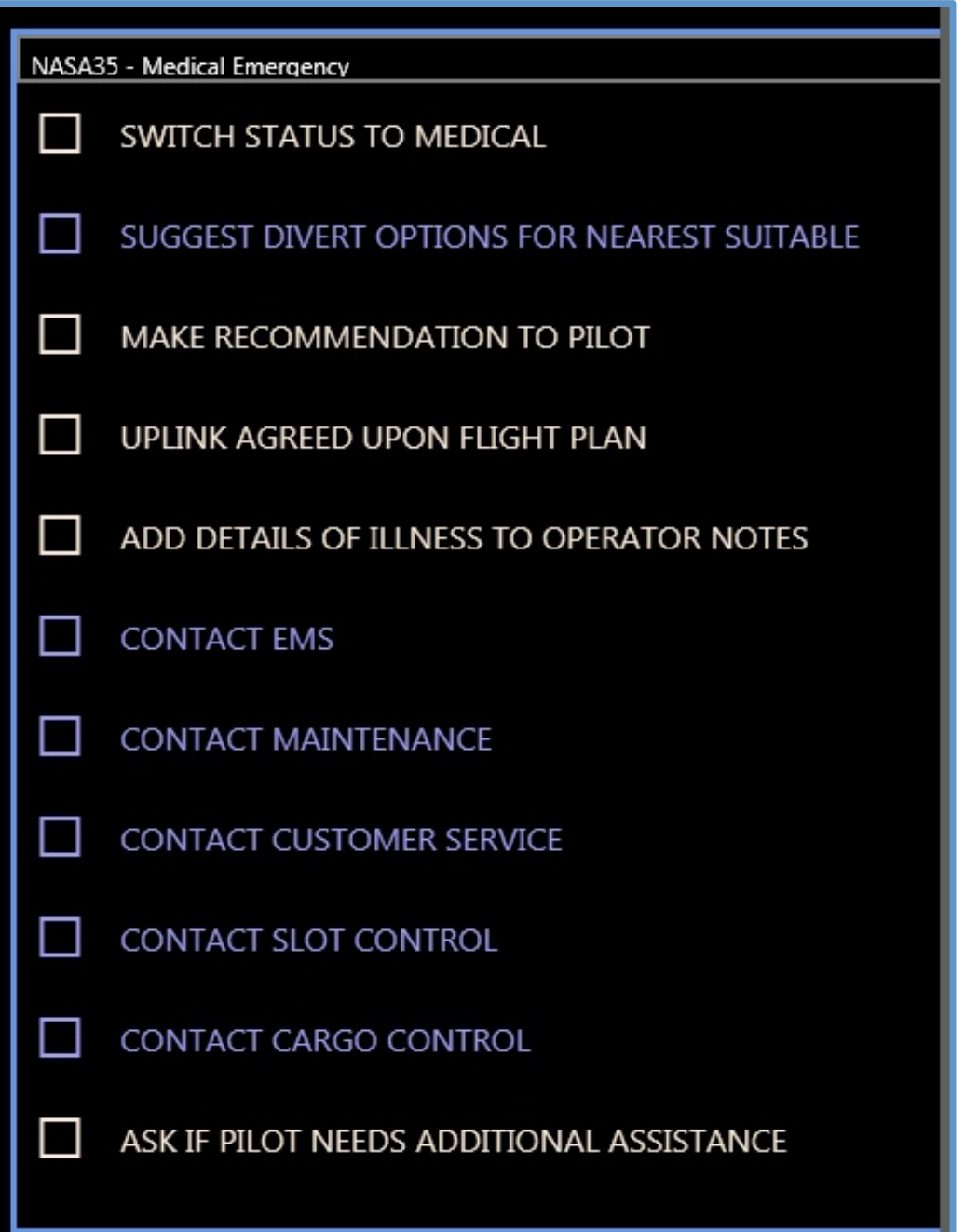




\section{Building in HAT Tenets to the Ground Station SJSU SANV OSE STATE}

- Transparency

- Divert reasoning and factor weights are displayed

- Numeric output from ACFP was found to be misleading by pilots. Display now uses English categorical descriptions.

- Bi-directional Communication

- Operators can change factor weights to match their priorities

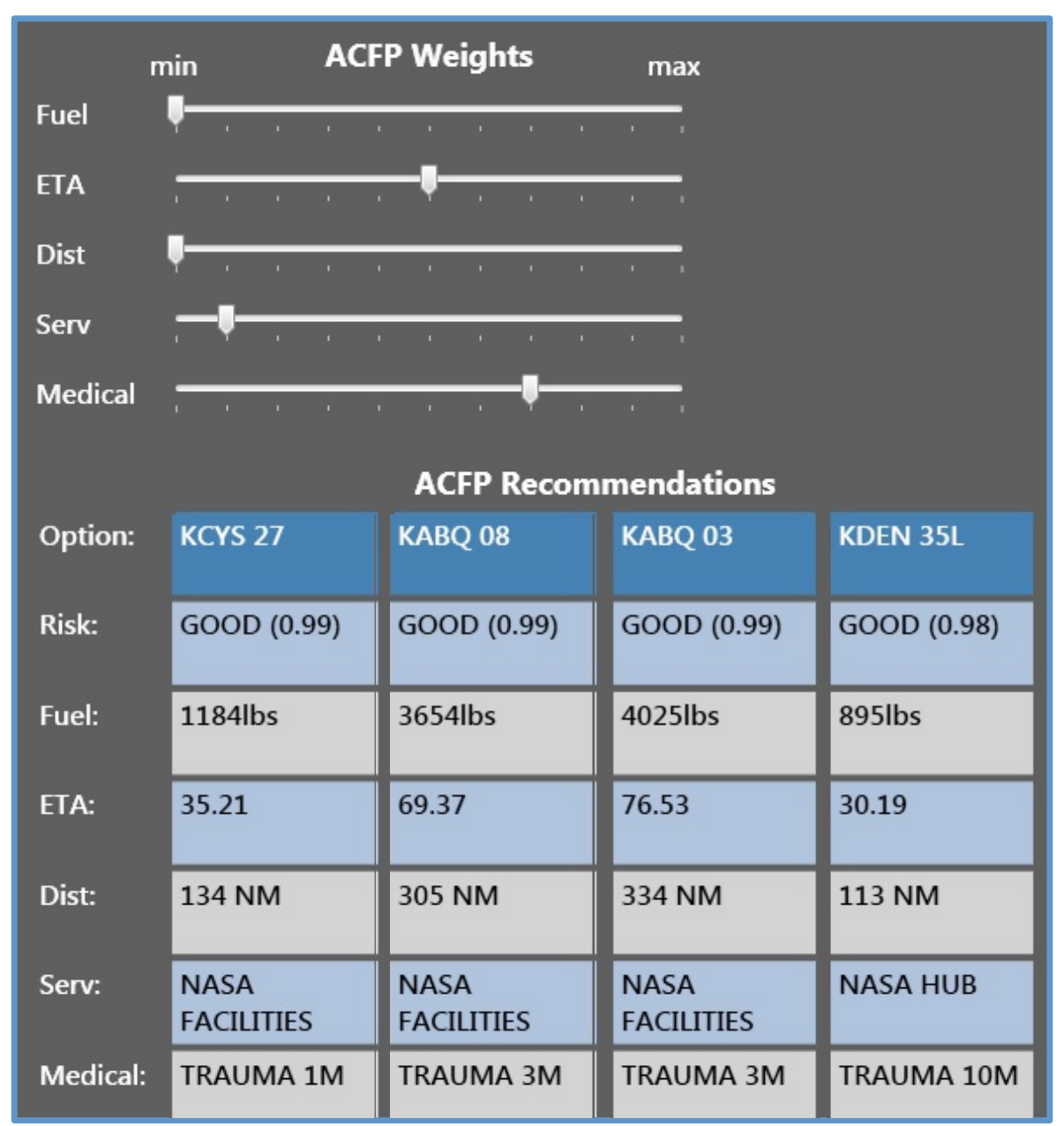




\section{HAT Simulation: Results}

- Participants preferred the HAT condition overall $(M=8.5, S D=0.55)$

- HAT displays were preferred with regard to:

- keeping up with operationally important issues $(M=8.67, S D=0.52)$

- ensuring the necessary situation awareness for the task $(M=8.67, S D=0.52)$

- integrating information from a variety of sources $(M=8.67, S D=0.52)$

- reducing workload necessary for the task $(M=8.33, S D=0.82)$

- efficiency $(M=8.33, S D=0.82)$

- Participants reported greater confidence that their diversion choice was appropriate in the HAT condition $(M=7.83, S D=1.47)$ compared to the No HAT condition $(M=6.33, S D=2.07 ; \mathrm{t}(5)=4.39, p=.01)$

- ACFP was rated as useful $(M=5.83, S D=0.82)$, particularly during emergency situations

- "Everything is easy and accessible in emergency situations. No need to consult many other programs to get various info." 


\section{HAT Simulation: Results}

- Supporting Bi-directional Communication

- ACFP weights

- improved automation's ability to handle unusual situations $(M=7.83, S D=1.60)$

- were useful in making divert decisions $(M=8.33, S D=0.82)$

- were liked $(M=8.33, S D=1.21)$

- "[the display] gave me the ability to see why, gave me control to change weights in variable(s)"

- Building in Transparency

- ACFP table

- was helpful in making divert decisions $(M=7.67, S D=1.51)$

- was liked $(M=8.33, S D=1.03)$

- "This [table] is wonderful... You would not find a dispatcher who would just be comfortable with making a decision without knowing why."

- Creating an Operator Directed Interface with Plays

- Electronic checklist

- was liked $(M=8.67, S D=0.52)$

- "This electronic checklist was easier because it was right there on the screen and it eliminated a couple of steps" 


\section{HAT Simulation: Summary}

- Participants liked where we were headed with the HAT concept

- Increased Situation Awareness

- Reduced Subjective Workload

- Things we didn't get quite right

- Participants didn't always understand what the goal of a play was

- Annunciations: People liked them but thought there were to many

- Voice Control: Did not work well. Need a more complete grammar, better recognition

- Things we didn't get to

- Airlines hate diverts. We need to put in support to help avoid them

- Plays need more structure (branching logic)

- Roles and responsibilities need to be more flexible

- Limited ability to suggest alternatives 


\section{Where next?}

- Running another part-task study with HAT features implemented on the flight deck

- Developing a software framework for creating HAT Agents

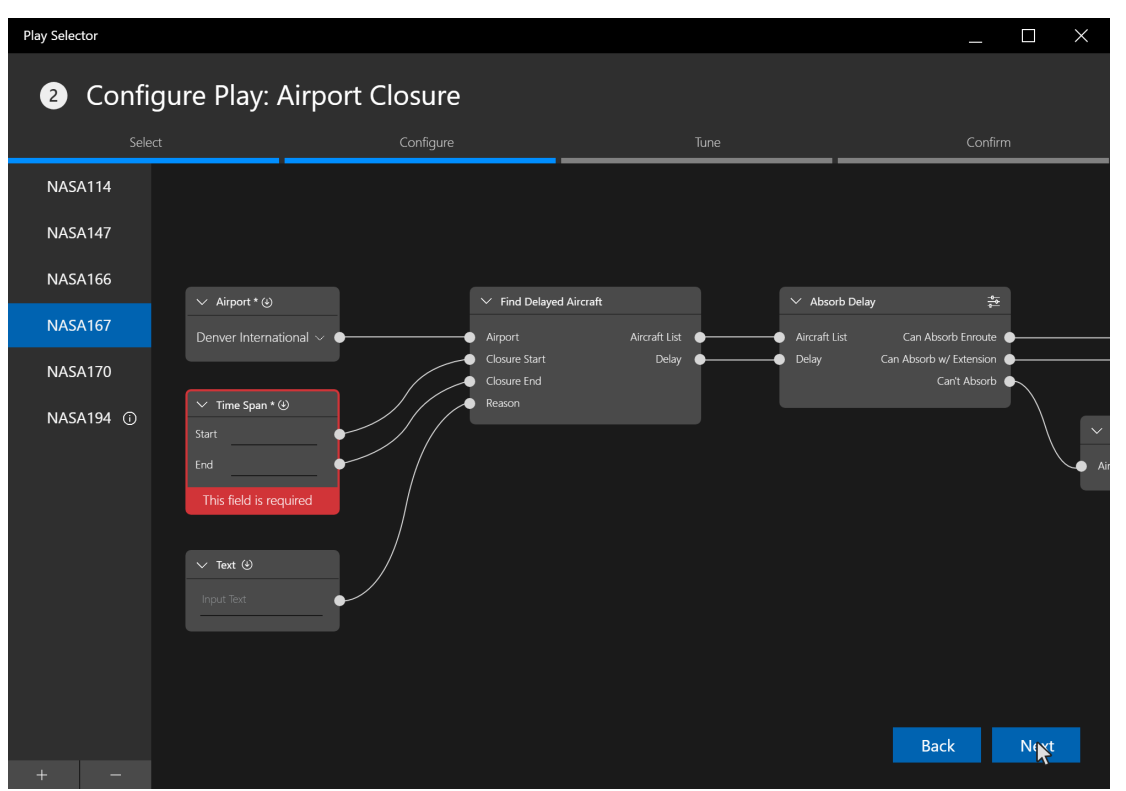

